\title{
ADAPTATION TO ALTERED SUPPORT AND VISUAL CONDITIONS DURING STANCE: PATIENTS WITH VESTIBULAR DEFICITS ${ }^{1}$
}

\author{
LEWIS M. NASHNER, ${ }^{*, 2}$ F. OWEN BLACK, $\ddagger$ AND CONRAD WALL, III \\ ${ }^{*}$ Neurological Sciences Institute, Good Samaritan Hospital and Medical Center, Portland, Oregon 97209 \\ and $\ddagger$ Department of Otolaryngology, University of Pittsburgh School of Medicine, Eye and Ear Hospital of Pittsburgh, \\ Pittsburgh, Pennsylvania 15213
}

Received August 5, 1981; Revised December 23, 1981; Accepted December 29, 1981

\begin{abstract}
Patients whose deficits were limited to clinically well qualified vestibular disorders have been exposed to a number of altered support surface and visual environments while standing unsupported. A six-degrees-of-freedom platform employing movable support surfaces for each foot and a movable visual surround deprived patients of normal inputs derived from a fixed level support surface and from an immobile surround. Various tests employing EMG, force, and body movement recording identified quantitative changes in the patients' strategy for the relative weighting of proprioceptive, vestibular, and visual inputs.

The most dramatic performance deficit of patients was their inability to suppress the influence of visual and proprioceptive inputs appropriately whenever motions of external surface disturbed the orientation information provided by these inputs. Thus, the more mildly afflicted patients experienced instability not so much because of the loss of vestibular inputs directly to posture but because of their inappropriate responses to proprioceptive inputs and vision. Discussion is centered on the role of vestibular input as an internal reference system for orientation about which adaptive changes in proprioceptive and visual inputs are made.
\end{abstract}

The role of vestibular inputs in maintaining the freely standing subject in a state of vertical equilibrium has been difficult to define, primarily because this system provides only a portion of the required orientation information. Changes in the orientation of a standing subject are sensed by "support surface" inputs (proprioceptive and cutaneous inputs responsive to the contact forces and motions of the feet upon the support surface), visual inputs (derived from linear and angular motions of the visual field), as well as vestibular inputs (derived from sway-related linear and angular accelerations of the head). However, the orientation information provided by support surface and visual inputs is potentially disrupted by the movements of the external surfaces to which these two senses are referenced. Therefore, support surface and visual inputs can be used to maintain vertical equilibrium only when their reference surfaces are fixed or their motions can be predicted in advance. In contrast,

\footnotetext{
${ }^{1}$ This work was conducted at the Neurological Sciences Institute and was supported jointly by National Institutes of Health Grants NS12661 (to L. M. N.) and NS-13286 (to F. O. B. and C. W.).

${ }^{2}$ To whom correspondence should be addressed at Neurological Sciences Institute, Good Samaritan Hospital and Medical Center. 1120 N. W. 20th Avenue, Portland, OR 97209.
}

the inertial-gravitational reference provided by the vestibular system is unaffected by changes in external surface conditions within most earth-bound environments. For this reason, Begbie (1967) ascribed to the vestibular system a critical role in maintaining vertical equilibrium under altered support surface and visual conditions. By observing the equilibrium of patients with diminished vestibular function, Martin (1965) suggested that input from the support surface provides the bulk of stability when stance is supported by a fixed, level surface. However, he concluded that vestibular inputs are essential for balance whenever support and/or visual surfaces are irregular or in motion. A logical extension of Martin's conclusion is that the normal system for a subject's strategy for the weighting of support surface, visual, and vestibular inputs to the equilibrium control is context dependent. Although two previous studies demonstrated context-dependent changes in the weighting of vestibular (Watt and Zucker, 1980) and support surface inputs (Nashner, 1976) to posture, neither these nor other studies have examined the process for establishing the weighting of inputs appropriate to a given sensory context.

When performing within sensory environments which include conflicts in the orientation information imparted 
by the three input modalities, the system for equilibrium control must include a process which correctly identifies and then selectively focuses upon the inputs providing the functionally most useful information. To accomplish this sufficiently fast to prevent the falling of a standing subject exposed unexpectedly to a sensory conflict, some pre-established strategy for conflict resolution is required. An internal reference system was fundamental to the concept of "efference copy" advanced by von Holst and Mittelstaedt (1950) and then expanded by Held (1961). According to this hypothesis, knowledge of intended movements is used to construct an "internal model" of orientation which then is used to distinguish between shifts in body orientation relative to the surround and changes in orientation of external objects relative to the body. Unfortunately, this process alone cannot describe context-dependent changes in the weighting of inputs to the equilibrium control system, since shifts in the orientation of the body may occur without prior knowledge due to the inherently unstable characteristics of the body or to external perturbations.

This project has tested experimentally the hypothesis that, within the system for equilibrium control, the vestibular sense of inertial-gravitational orientation is a reference against which conflicting support surface and visual inputs are suppressed quickly. The initial assumption was based upon the clinical observation that vestibular deficit patients could not cope effectively with disturbances in support surface and visual inputs (e.g., Martin, 1965; Begbie, 1967) and the evidence that the human vestibular system is an accurate inertial-gravitational transducer at the frequencies and amplitudes of motion characteristic of normal stance and walking activities (e.g., Meiry, 1966). The experimental approach was to compare the equilibrium control strategies of normal subjects and a highly select group of patients with clinically well described vestibular abnormalities as each group performed within a variety of altered support surface and visual environments. The most significant finding was that patients with mild, by clinical standards, vestibular impairment performed in the absence of useful support surface and visual inputs; yet these same patients responded inappropriately and lost balance when exposed to conflicting support surface and visual stimuli. In contrast, normal subjects performed equally well when deprived of support surface and visual stimuli or exposed to conflicting stimuli, suggesting that the fundamental abnormality of the patients was not so much the loss of direct vestibular inputs to posture but rather the inability to suppress conflicting support surface and visual inputs quickly.

\section{Materials and Methods}

Patient selection. Candidates with vestibular lesions were chosen from the clinical services at the Eye and Ear Hospital of Pittsburgh. Each candidate received a neurologic and vestibular examination in order to quantify the extent of vestibular dysfunction and to assure freedom from other CNS disorders affecting motor control. Clinical assessments of vestibular function included the quantitative analysis of the vestibulo-ocular reflex (VOR) (Wall et al., 1978) and the analysis of postural sway while patients maintained four fixed postural configurations (Black et al., 1978). Twelve participants were selected utilizing the following criteria: (1) freedom from other CNS disorders, (2) ability to stand and walk without assistance, and (3) high degree of motivation to maintain a normal as possible life-style (i.e., well compensated). We also rejected candidates reporting vertigo or other symptoms which suggested an exaggerated sensitivity to movement or vestibular activity in the absence of head movement. Patients were grouped within three categories, depending upon the results of the clinical tests. Category A was reserved for 1 patient with complete loss of vestibular function. Category $B$ included 5 patients with significant, though incomplete, disruption of vestibular function. The remaining 6 category $\mathrm{C}$ patients were very mildly afflicted or were clinically in remission at the time of testing. Table I summarizes the clinical history and category rating of each of the 12 patients. Two agematched normal subjects also were included in the study in order to assure that any performance differences between the vestibular patients and normal subjects (previous studies had already tested normal subjects aged 20 to 32 years in several of the paradigms incorporated in this project; Nashner, 1972, 1976; Nashner and Berthoz, 1978) were not dependent upon the more advanced age of the patient population.

Platform test procedures. Each test procedure was described thoroughly in a previous publication (Nashner, 1971, 1976; Nashner and Berthoz, 1978). These procedures involved the use of an instrumented platform system (Fig. 1) including two movable support surfaces (one for each foot, each independently translates in horizontal and vertical directions and rotates about an axis co-linear with the ankle joint) and a movable visual surface (a 1-m square enclosure open on the back and bottom sides which rotates about an axis co-linear with the ankle joints). Strain gauges incorporated within each support surface measured the anteroposterior distribution of vertical forces (torque) exerted by the foot. A potentiometer attached to each subject's hips via a lightweight rod measured the anteroposterior (AP) sway orientation of the participant's center of gravity with respect to the ankle joints.

Brief support surface movements elicited automatic postural adjustments. Translating both support surfaces in the anteroposterior direction, as illustrated in Figure $1 A( \pm 30 \mathrm{~cm} / \mathrm{sec}$ for $250 \mathrm{msec})$, caused the subject to sway principally about the ankle joints in a direction opposite that of the platform motion (Nashner, 1977). In contrast, when both support surfaces were rotated transiently in "toes up" and "toes down" directions $\left( \pm 20^{\circ} / \mathrm{sec}\right.$ for 250 $\mathrm{msec}$ ), the ankle joints rotated at approximately the same rate as in the above AP sway test, but as shown in Figure $1 B$, ankle rotations were now unrelated to the AP sway motions of the body.

Platform surfaces were moved continuously (50-sec intervals) to alter the conditions under which the patient performed. Support surface inputs related to AP sway orientation were disrupted in Figure $1 C$ by an "ankle stabilization" procedure. Under this condition, the platform support surfaces rotated in direct proportion to the AP sway motions of the body, thereby preventing 
TABLE I

Part 1: Vestibulo-ocular reflex test results on patients

\begin{tabular}{|c|c|c|c|c|c|c|}
\hline \multirow[b]{2}{*}{ Patient } & \multirow[b]{2}{*}{ Diagnosis } & \multicolumn{4}{|c|}{ Rotation Test Results ${ }^{a}$} & \multirow[b]{2}{*}{ Clinical Interpretation } \\
\hline & & \multicolumn{2}{|c|}{ Gains $^{b}$} & \multirow{2}{*}{$\begin{array}{c}\begin{array}{c}\text { Root Mean } \\
\text { Square } \\
\text { Velocity }\end{array} \\
0^{c}\end{array}$} & \multirow[t]{2}{*}{ Symmetry } & \\
\hline 1 & Streptomycin ototoxicity & $0^{c}$ & $0^{c}$ & & & No VOR responses \\
\hline 2 & Left labyrinthectomy and right $\mathrm{BPPN}^{d}$ & 3.1 & 1.6 & 18.1 & $\mathrm{Ab}^{e}$ & Spontaneous nystagmus with eyes closed \\
\hline 3 & Right Ménière's disease & 4.0 & 1.2 & 18.1 & $\mathrm{Ab}$ & Spontaneous nystagmus with eyes closed \\
\hline 4 & Left Ménière's disease & 4.4 & 2.1 & 21.7 & $\mathrm{Ab}$ & Spontaneous nystagmus with eyes closed \\
\hline 5 & Left Ménière's disease & 3.5 & 1.4 & 16.8 & $\mathbf{N}^{\prime}$ & Normal VOR parameters \\
\hline 6 & $\begin{array}{l}\text { Left labyrinthectomy and right Ménière's } \\
\text { disease }\end{array}$ & 2.5 & 1.1 & 13.0 & $\mathbf{N}$ & Normal VOR parameters \\
\hline 7 & Left Ménière's disease & $1.6^{c}$ & $0.9^{c}$ & 11.4 & $\mathbf{N}$ & Low VOR gains \\
\hline 8 & Right Ménière's disease & $1.6^{\mathrm{c}}$ & $0.6^{c}$ & $8.0^{\mathrm{c}}$ & $\mathrm{N}$ & Low VOR gains \\
\hline 9 & Left Ménière's disease & 4.3 & 2.0 & 20.5 & $\mathrm{Ab}$ & Spontaneous nystagmus with eyes closed \\
\hline 10 & Bilateral Ménière's disease & $0.25^{c}$ & $0.03^{c}$ & $3.2^{c}$ & $\mathbf{N}$ & Low VOR gains \\
\hline 11 & Right Ménière's disease & 4.0 & 1.6 & 19.1 & $\mathrm{Ab}$ & Spontaneous nystagmus with eyes closed \\
\hline 12 & Left Ménière's disease & 3.0 & 1.5 & 15.1 & $\mathbf{N}$ & Normal VOR parameters \\
\hline
\end{tabular}

${ }^{a}$ Methods for rotational testing have been described by Wall et al. (1978).

${ }^{b}$ Gains (re-acceleration) were measured at 0.02 and $0.05 \mathrm{~Hz}$, respectively.

'Abnormally low values.

${ }^{d}$ BPPN is a condition of fluid capula-specific gravity imbalance.

e Abnormal (Ab) symmetry occurs when mean VOR velocity is significantly different from 0.

' $N$, normal.

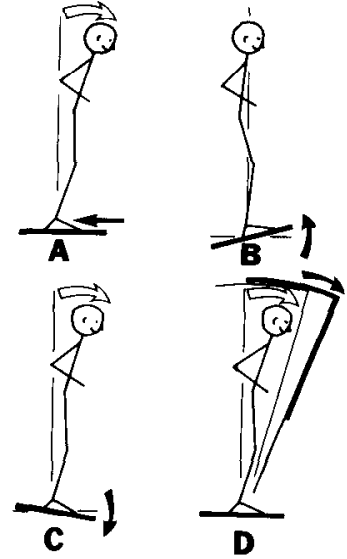

Figure 1. Stimulus modalities of the movable platform system. $A$, AP sway induced by translation of the support surface; $B$, rotation of the ankle joints in place; $C$, stabilization of the support surface inputs; $D$, stabilization of the visual input. Solid arrows show the directions of platform component motions. Open arrows show body sway motions.

changes in the orientation of the support surface with respect to the AP orientation of the body center of mass. In a similar manner, disruption of visual orientation inputs, "visual stabilization," was accomplished by continuously rotating the visual surround in direct proportion to the AP orientation of the body (Fig. 1D). The hydraulic servomechanisms which rotated the support and the visual surfaces were each sufficiently fast $(0$ to 5 $\mathrm{Hz}$ frequency response) to track the AP sway motions of the subjects, which occurred principally at frequencies below $1.0 \mathrm{~Hz}$ (Black et al., 1978). During both ankle and visual stabilization procedures, the gain of surface motion relative to that of body sway could be set at any level between 0 (fixed surfaces) and 1.0 (surface and body motions in direct proportion). The major source of stabilization error where gains were set to 1.0 was the mechanical measure of AP sway. Using photographic and video measures of AP sway and platform motions under this condition, we estimated that stabilization accuracy was within $\pm 5 \%$. (In depth analysis of stabilization errors and their potential significance is included under "Discussion.")

The temporal and spatial structure of automatic EMG adjustments (those commencing 95 to $110 \mathrm{msec}$ following imposition of transient support surface displacements) was analyzed by processing (full wave rectification and filtration at 0 to $40 \mathrm{~Hz}$ ) the surface EMG signals from four leg muscles: gastrocnemius, anterior tibialis, hamstrings, and quadriceps (see Nashner, 1977; Nashner et al., 1979). Context-dependent changes in the amplitude of automatic EMG adjustments during sequences of five like surface displacements, "adaptation ratios," were defined as the amplitude sum of the first two automatic EMG responses (determined by numerically integrating each processed EMG signal over 75-msec intervals commencing at the onset of the automatic response) divided by the amplitude sum of the last two automatic EMG responses.

The degree of postural stability maintained by a patient during a 50 -sec stance trial was characterized by a "performance ratio," the numerical integral of the rectified AP sway signal (steady state offset removed) scaled to be a fraction of the maximum AP sway amplitude possible during the feet together stance (approximately $8^{\circ}$ forward to $4^{\circ}$ backward). Performance ratio values of 1.0 were assigned to a trial when a patient exceeded these limits and was forced to grasp the handrail, take a step, or be supported by the assistant.

Protocol. Fourteen participants ( 2 normal subjects and 12 patients) were each tested during three 1 -hr sessions. 
TABLE I

Part 2: Static balance tests on patients

\begin{tabular}{|c|c|c|c|c|c|c|}
\hline \multirow[b]{2}{*}{ Patient } & \multirow[b]{2}{*}{ Classification $^{a}$} & \multicolumn{4}{|c|}{ Posturograph Tests ${ }^{b}$} & \multirow[b]{2}{*}{ Clinical Interpretation } \\
\hline & & $\begin{array}{c}\text { Romberg Eyes } \\
\text { Open }\end{array}$ & $\begin{array}{c}\text { Romberg Eyes } \\
\text { Closed }\end{array}$ & $\begin{array}{c}\text { Tandem Romberg } \\
\text { Eyes Open }\end{array}$ & $\begin{array}{c}\text { Tandem Romberg } \\
\text { Eyes Closed }\end{array}$ & \\
\hline 1 & A & $260,276^{c}$ & 539,782 & 962,1183 & $\mathrm{Us},{ }^{d} 1327$ & Peripheral vestibular pattern ${ }^{e}$ \\
\hline 2 & B & 386,492 & 483,477 & 1162,1246 & Us, 2854 & Peripheral vestibular pattern \\
\hline 3 & $\mathbf{B}$ & 292,84 & 221,77 & 292,116 & Us, Us & Peripheral vestibular pattern \\
\hline 4 & $\mathbf{B}$ & 66,75 & 149,94 & 115,126 & Us, Us & Peripheral vestibular pattern \\
\hline 5 & $\mathbf{B}$ & 74,58 & 114,130 & 116,180 & Us, Us & Peripheral vestibular pattern \\
\hline 6 & $\mathbf{B}$ & 71,103 & 157,100 & 164,100 & Us, Us & Peripheral vestibular pattern \\
\hline 7 & $\mathrm{C}$ & 99,180 & 664,387 & 81,60 & 726,160 & Normal balance \\
\hline 8 & C & 131,75 & 122,172 & 192,502 & 1045,952 & Normal balance \\
\hline 9 & $\mathrm{C}$ & 165,108 & 682,643 & 452,173 & Us, Us & Peripheral vestibular pattern \\
\hline 10 & $\mathrm{C}$ & 76,63 & 137,627 & 178,112 & 1871,269 & Normal balance \\
\hline 11 & C & 152,40 & 129,184 & 68,48 & 270,192 & Normal balance \\
\hline 12 & $\mathrm{C}$ & 60,90 & 640,304 & 77,99 & 428,643 & Normal balance \\
\hline \multicolumn{2}{|c|}{ Normal range $f$} & $54-438$ & $128-674$ & $61-473$ & $183-1492$ & \\
\hline
\end{tabular}

${ }^{a}$ Classifications are based upon a composite of all test results; A most severe to C least severe.

${ }^{b}$ The methods for static posturography tests have been described by Black et al. (1978).

${ }^{c}$ The numbers give power spectral integral scores (sway) for first and second attempts, respectively.

${ }^{\alpha}$ Unstable (Us) and could not complete the trial.

${ }^{e}$ Refers to instances where the patient is significantly more unstable with eyes closed on one or both tests.

'The normal range for power spectral integral scores has been defined by Black et al. (F. O. Black, C. Wall, III, H. E. Rockett, and R. Kitch, submitted for publication).

Because disorientation and instability were risks during the assessment of vestibular patients, tests were imposed in order of increasing difficulty during the first one and one-half sessions. Subsequent sessions were used to examine possible practice and set dependent changes in overall performance.

A typical ordering of tests is outlined in Table II. The first 3 tests quantified the performance of patients under the three different visual conditions (normal, eyes closed, and stabilized vision) when they were provided a fixed support surface. The subsequent 4 support surface displacement tests examined the structural and adaptive properties of automatic EMG adjustments. Performance measures were repeated in tests 8 to 10 for the three different visual conditions, except now patients stood with the support surface stabilized. The final 2 tests determined the latency of the EMG adjustments of patients deprived of both support surface and visual inputs. Because it was probable that some patients would lose their balance during tests 9 and 10, stabilization gains during these trials were set initially at 0.5 and then periodically increased every $15 \mathrm{sec}$. Gain increments were 0.05 to 0.2 , depending upon the degree of stability of the subject. However, performance ratios were computed only at the highest gain values at which the subject maintained stability for the 50-sec interval.

\section{Results}

Performance under fixed support surface conditions. When the sway excursions of patients were scaled in proportion to the maximum possible amplitudes for the feet together stance, differences in performance among the patients and normal subjects were relatively small under the three fixed support surface tests (Table II, tests 1 to 3 ), suggesting that patients were relatively efficient in utilizing support surface inputs. The sway
TABLE II

Typical test sequence for vestibular patients

\begin{tabular}{|c|c|c|}
\hline Type of Test & Sensory Conditions & $\begin{array}{c}\text { Number and } \\
\text { Duration of } \\
\text { Trials } \\
\end{array}$ \\
\hline 1. Performance & $\begin{array}{l}\text { Normal (fixed) support } \\
\text { and visual surfaces }\end{array}$ & $2,50 \mathrm{sec}$ \\
\hline 2. Performance & $\begin{array}{l}\text { Normal support surface, } \\
\text { eyes closed }\end{array}$ & $2,50 \mathrm{sec}$ \\
\hline 3. Performance & $\begin{array}{l}\text { Normal support surface, } \\
\text { stabilized vision }\end{array}$ & $2,50 \mathrm{sec}$ \\
\hline $\begin{array}{l}\text { 4. Transient support } \\
\text { surface translations }\end{array}$ & $\begin{array}{l}\text { Normal support and vis- } \\
\text { ual conditions }\end{array}$ & $\begin{array}{l}5 \text { forward, } 1 \\
\text { sec }\end{array}$ \\
\hline $\begin{array}{l}\text { 5. Transient support } \\
\text { surface rotations }\end{array}$ & $\begin{array}{l}\text { Normal support and vis- } \\
\text { ual conditions }\end{array}$ & $\begin{array}{l}5 \text { "toes up," } \\
1 \text { sec }\end{array}$ \\
\hline $\begin{array}{l}\text { 6. Transient support } \\
\text { surface translations }\end{array}$ & $\begin{array}{l}\text { Normal support and vis- } \\
\text { ual conditions }\end{array}$ & $\begin{array}{l}5 \text { backward, } \\
1 \text { sec }\end{array}$ \\
\hline $\begin{array}{l}\text { 7. Transient support } \\
\text { surface rotations }\end{array}$ & $\begin{array}{l}\text { Normal support and vis- } \\
\text { ual conditions }\end{array}$ & $\begin{array}{l}5 \text { "toes } \\
\text { down," } 1 \\
\text { sec }\end{array}$ \\
\hline 8. Performance & $\begin{array}{l}\text { Stabilized support sur- } \\
\text { face, normal vision }\end{array}$ & $2,50 \mathrm{sec}$ \\
\hline 9. Performance & $\begin{array}{l}\text { Stabilized support sur- } \\
\text { face, eyes closed }\end{array}$ & $2,50 \mathrm{sec}$ \\
\hline 10. Performance & $\begin{array}{l}\text { Stabilized support and } \\
\text { visual surfaces }\end{array}$ & $2,50 \mathrm{sec}$ \\
\hline $\begin{array}{l}\text { 11. Transient support } \\
\text { surface translations }\end{array}$ & $\begin{array}{l}\text { Stabilized support sur- } \\
\text { face, eyes closed }\end{array}$ & $\begin{array}{l}5 \text { forward, } 1 \\
\text { sec }\end{array}$ \\
\hline $\begin{array}{l}\text { 12. Transient support } \\
\text { surface translations }\end{array}$ & $\begin{array}{l}\text { Stabilized support sur- } \\
\text { face, eyes closed }\end{array}$ & $\begin{array}{l}5 \text { backward, } \\
1 \text { sec }\end{array}$ \\
\hline
\end{tabular}

excursions of all patients were well below the limits of stability when freely standing under fixed support surface conditions, whether or not vision was disturbed by eye closure or by stabilization of the visual surrounds. The 12 patients and 2 age-matched normal subjects have been ordered numerically in Figure 2 according to the average performance ratios achieved by each while performing 
under the six conditions (see also Fig. 4 for performance ratios achieved under stabilized support surface conditions). The inset in Figure 2 compares the platform and the independently derived clinical rating scales (see Table I) of the 12 patients.

Consistent with the above findings, the temporal and spatial structure of the automatic EMG adjustments of patients was indistinguishable from that of normal subjects whenever support surface displacements (Table II, tests 4 and 5) were imposed during normal sensory conditions. For example, in Figure $3, A$ and $B$ show, respectively, that ensemble averages of the forward and backward automatic EMG adjustments of the most severely afflicted subject, patient 1 , commenced at 90 - to 110 msec latencies in the stretching ankle joint muscle and in equal proportion after an additional 5- to 15 -msec delay in the appropriate upper leg synergist. Figure 6 shows that the response latencies of all 12 patients were equally precise under this test condition. The torque and AP sway records shown in Figure 3 also represent how the automatic EMG responses of patients generated resistive forces sufficient to arrest AP sway within 1 sec.

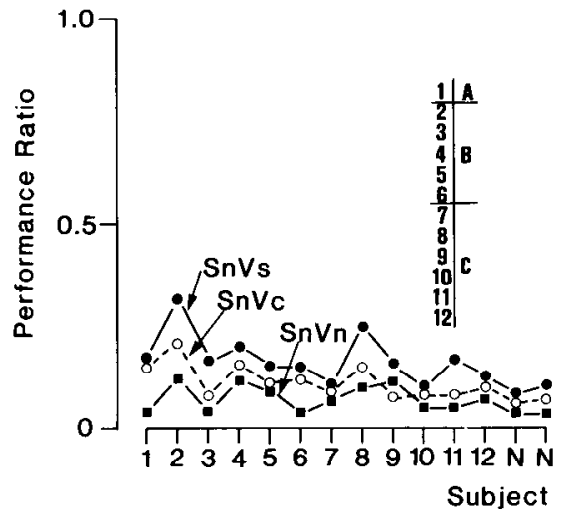

Figure 2. Performance ratios of patients (numbered 1 through 12) and 2 age-matched normal subjects $(N)$ under fixed support surface conditions with normal vision $\left(\mathbb{a}, S_{N} V_{N}\right)$, with eyes closed $\left(O, S_{N} V_{C}\right)$, and with the visual surface stabilized $\left(O, S_{N} V_{S}\right)$. The inset on the right shows the clinical category ratings of the patients (see Table I).

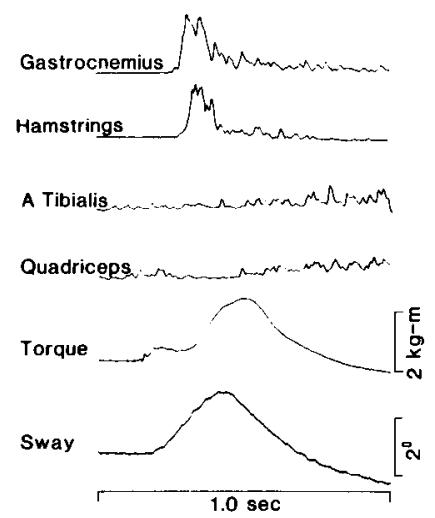

A
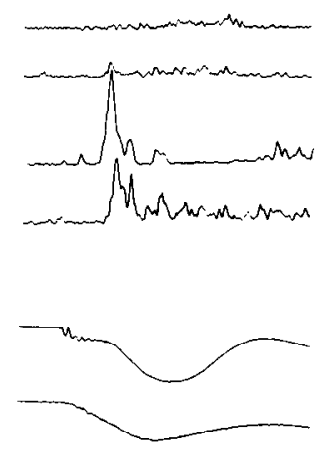

B

Figure 3. Ensemble averages of the EMG, torque, and sway responses of five consecutive trials of patient 2 to forward AP sway perturbations $(A)$ and to backward AP sway perturbations (B) under fixed surface conditions $\left(\mathrm{S}_{\mathrm{N}} \mathrm{V}_{\mathrm{N}}\right)$.

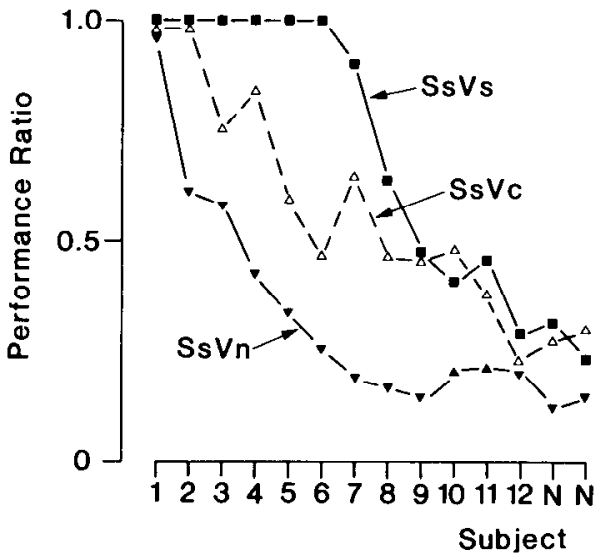

Figure 4. Performance ratios of patients and normal subjects under stabilized support surface conditions with normal vision $\left(\triangle, S_{S} V_{N}\right)$, eyes closed $\left(\triangle, S_{S} V_{C}\right)$, and the visual surface also stabilized (ם, $\left.S_{S} V_{S}\right)$.

Performance under stabilized support surface conditions. Under all stabilized support surface conditions, performance ratios were larger and varied considerably from participant to participant as shown in Figure 4. With eyes open $\left(\mathrm{S}_{\mathrm{S}} \mathrm{V}_{\mathrm{N}}\right)$, all except patient 1 maintained balance with a stabilizing gain of 1.0 , the level at which relative sway motions between the subject and both external surfaces were eliminated completely. Patient 1 maintained stability only when gains were 0.8 or less. Eye closure $\left(\mathrm{S}_{\mathrm{S}} \mathrm{V}_{\mathrm{C}}\right)$ increased the performance ratios of all participants. Nevertheless, all but patients 1 and 2 continued to maintain balance with stabilizing gains of 1.0. With eyes closed, the maximum stabilizing gain achieved by patient 1 decreased to 0.70 , while that of patient 2 was 0.8 . When subsequently reopening their eyes under stabilized visual conditions $\left(\mathrm{S}_{\mathrm{S}} \mathrm{V}_{\mathrm{S}}\right)$, patients 3 to 6 (who had just completed this task successfully with their eyes closed) now lost balance, while the performance ratios of patients 7 and 8 increased to near the stable limits. Under $\mathrm{S}_{\mathrm{S}} \mathrm{V}_{\mathrm{S}}$ conditions, the maximum gains at which patients 1 to 6 could remain stable all ranged between 0.7 and 0.8 .

The impression gained during the above tests was that the performance limits of patients 1 to 6 were abruptly rather than gradually met as stabilizing gains were increased above 0.7. In order to examine this impression more carefully, support surface translations were imposed unexpectedly while patients 1,4 , and 6 performed with stabilizing gains set 0.05 below the limits of their capability. The right side of Figure 5 illustrates a representative example of the sequel. Although oscillating at her limits of stability under $\mathrm{S}_{\mathrm{S}} \mathrm{V}_{\mathrm{S}}$ conditions (gain, 0.8 ; performance ratio, 85), patient 4 performed the same task with much less sway when the gain was reduced (gain, 0.75; performance ratio, 32). When horizontal support surface perturbations (arrow) were imposed at this slightly lower gain, the additional sway motion was attenuated quickly. Gain reductions of 0.05 below maximum also caused dramatic decreases in the performance ratios of patients 1 and 6 , and the larger sway motions induced by support surface perturbations at these slightly reduced gain levels were reduced quickly from 0.98 to 0.56 in patient 1 and from 0.95 to 0.40 in patient 6 . 
To test the effects of practice upon the performance limits of patients who did not initially achieve gains of 1.0 under stabilized ankle and visual conditions, subjects 1,4 , and 6 agreed to make repeated attempts. During these trials, gains were set at maximum stable values and then occasionally elevated to observe the effects of practice. However, only subject 6 significantly improved; she finally achieved a gain of 1.0 after 12 attempts.

As vestibular patients approached the limits of stability, they tended to oscillate back and forth at relatively fixed frequencies and amplitudes. When asked to perform with stabilizing gains set 0.05 above their performance limits, the amplitudes of oscillations grew slowly until motions of the center of body mass exceeded the limits of the surface of foot support and the subject lost balance, grasped the safety rail, or stumbled. Generally, the sway oscillations were at frequencies of $0.7 \mathrm{~Hz}$ or above when produced under stabilized surface conditions with eyes closed $\left(\mathrm{S}_{\mathrm{S}} \mathrm{V}_{\mathrm{C}}\right)$ and were reduced to 0.1 to $0.2 \mathrm{~Hz}$ when eyes were subsequently reopened within a stabilized visual condition $\left(\mathrm{S}_{\mathrm{S}} \mathrm{V}_{\mathrm{S}}\right)$. Figure 5 illustrates examples of the regular sway oscillation records as patient 1 performed under these two conditions.

EMG adjustments also were elicited by translating the support surfaces under stabilized support surface conditions with eyes closed $\left(\mathrm{S}_{\mathrm{S}} \mathrm{V}_{\mathrm{C}}\right)$ (Table II, tests 11 and 12$)$ in order to assess the ability of patients to respond to AP sway perturbations in the absence of useful support surface and visual inputs. Findings were again consistent with the preceding performance tests. The response latencies of patients 3 to 12 were all within the limits established for normal subjects (see also Nashner, 1971, 1972), while the response latencies of patients 1 and 2 , who lost balance performing under this condition, were abnormally delayed (see Fig. 6). However, despite the response time delays, the spatial structure of EMG adjustments in patients 1 and 2 still resembled that of normal subjects.

Performance under rotating support surface conditions. Patients were exposed alternately to sequences of either five support surface translations or five support surface rotations (support surface inputs now inappropriate for AP sway stabilization) in order to assess their ability to attenuate automatic EMG adjustments under

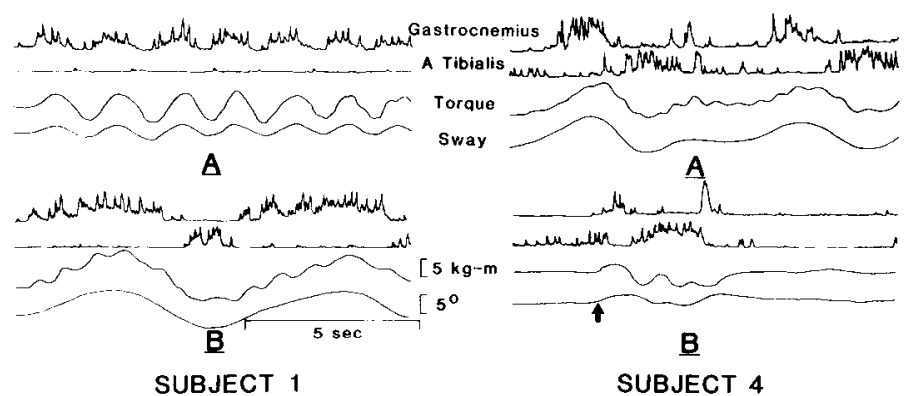

Figure 5. Individual EMG, torque, and AP sway records of two patients. Left, Data showing patient 1 standing with stabilized support surface and eyes closed (gain, $0.7 ; A$ ) and with stabilized support and visual surface (gain, $0.7 ; B$ ). Right, Data showing patient 4 standing with stabilized support and visual surfaces with gain levels of $0.8(A)$ and $0.75(B)$. The arrow shows the onset time of brief support surface translation.

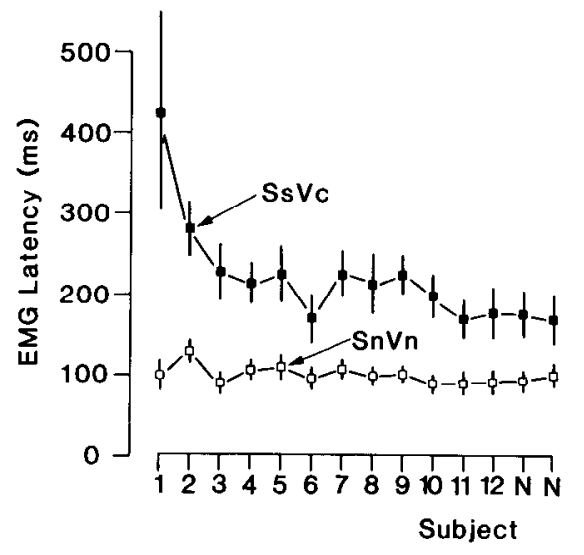

Figure 6. Average ( $\pm \mathrm{SD}$ ) latencies of EMG responses to forward (gastrocnemius) and backward (tibialis anterior) AP sway perturbations under two conditions, normal fixed support and visual surfaces $\left(\square, S_{N} V_{N}\right)$ and stabilized support surface with eyes closed $\left(\square, S_{S} V_{C}\right)$.

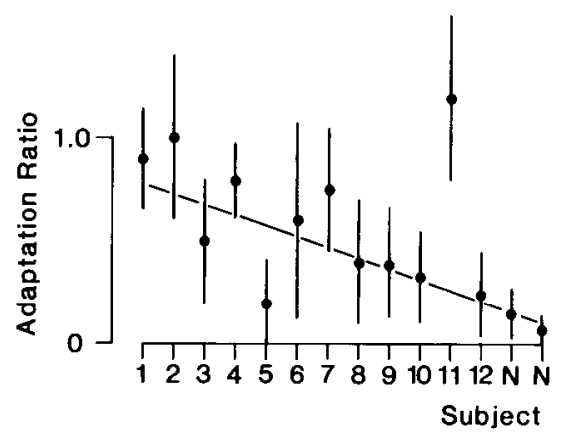

Figure 7. Average ( $\pm \mathrm{SD}$ ) adaptation ratios for patients and normal subjects subjected to sequences of five unexpected support surface rotations. A least squares linear regression line was fitted to the data, excluding that of patient 11 .

conditions in which they contribute to sway instability. With the exception of patient 11 , there was a definite correspondence between this and the preceding visual conflict tests; the more severely afflicted patients did not attenuate systematically the automatic EMG adjustments in stretching ankle joint muscles during rotational support surface displacements. To illustrate this observation, adaptation ratios for the 12 patients and 2 normal subjects are shown in Figure 7, and a least squares linear regression line has been fit to the data (excluding patient 11). We have no reasonable explanation, based upon our vestibular tests, for the inability of patient 11 to adapt to support surface rotations.

\section{Discussion}

Patients can be subdivided into three groups based upon their overall performance in equilibrium control tests. (1) The two most severely afflicted patients (1 and 2 ) were dramatically impaired in their ability to maintain stability when deprived of support surface and visual inputs (Fig. 4), and the latencies of their equilibrium reactions were significantly longer under these conditions (Fig. 6). (2) The second group of patients (3 to 8 ), whose primarily clinical indications were asymmetrics or lower than normal gains, were able to stand in the absence of 
useful support surface and visual inputs but lost balance or were highly destabilized by the introduction of conflicting visual (Fig. 4) or support surface (Fig. 7) inputs. (3) The third group of patients (9 to 12) performed nearly as well as normal subjects under sensory deprived and sensory conflict conditions.

We shall develop the argument here that vestibular inputs play two important roles within a hierarchically organized system for equilibrium control. At a hierarchically low level, a weighted sum of orientation inputs derived from the vestibular system as well as from the support surface and vision directly mediates the activity of postural muscles. At a hierarchically higher level, vestibular inputs provide the orientational reference against which conflicts in support surface and visual orientation inputs are identified rapidly. Of these two functions, the second appears to be the most critical, as vestibular input sufficient to maintain stability under sensory deprived conditions was retained by all but the few patients with severely disrupted receptor function, whereas asymmetrics and lowered gains were sufficient to impair a patient's ability to reweight inputs rapidly following the introduction of sensory conflicts. However, before the system for the rapid, context-dependent reweighting among sensory inputs can be addressed in detail, it is necessary to examine briefly the hierarchically lower level systems for support surface, vestibular, and visual mediation of postural activities.

Support surface input to equilibrium. When the support surface is fixed, the ankle joints are the major axis about which shifts in orientation of the center of body mass occur relative to the body's base of support (Nashner, 1977). Motion about the knees and hips also can be significant during stance; however, evidence suggests that these motions are coordinated to minimize shifts in the overall center of body mass (e.g., Gurfinkel et al., 1971). Because the ankle joints are a major axis for sway, forces resisting changes in positions of the ankle joints are critical for the maintenance of the vertical orientation of the body under fixed surface conditions. The fact that automatic EMG adjustments are mediated primarily by local support surface inputs was demonstrated by the similar temporal and spatial structure of automatic responses when elicited by AP sway and by rotating the support surface (Nashner, 1977).

The powerful stabilizing influence of automatic EMG adjustments mediated by support surface inputs is consistent with the low performance ratios achieved by all participants under the three visual conditions in which the support surface was fixed (Fig. 2). This observation also explains why linear (Lestienne et al., 1977) and circular (Dichgans et al., 1975) visual stimuli imposed upon subjects standing upon fixed support surfaces resulted in sway excursions less than $1^{\circ}$ or $2^{\circ}$, even though the rates of motion stimulation in both studies were high compared to those normally associated with sway. However, EMG adjustments sufficiently strong to compensate AP sway perturbations within 1 sec under fixed support surface conditions are equally potent in upsetting balance when inappropriately recruited by changes in the orientation of the support surface relative to the subject. Inability to suppress this component of response was one reason why vestibular patients often lost balance when confronted with support surface rotations (Fig. 7). In contrast, normal subjects performing under this stimuli condition quickly attenuated the amplitudes of automatic adjustments (Nashner, 1976).

Vestibular and visual inputs to equilibrium. Our experiments did not provide evidence of a form which would enable quantification of direct vestibular and visual inputs to posture beyond that already defined elsewhere. Demonstration that a patient completely devoid of vestibular input responded much more slowly to AP sway perturbations and could not stand upon the stabilized support surface under any visual condition supports several previous hypotheses, namely that the EMG adjustments at 175 - to 250 -msec latencies in normal subjects performing under this condition (Nashner, 1971) are, in fact, mediated by the vestibular inputs and that direct visual inputs alone are not sufficiently fast to stabilize AP sway (Lestienne et al., 1977). However, a number of other studies already showed that visual inputs to posture in the dog (Talbott and Brookhart, 1980) and in man (Lee and Lishman, 1975; Soechting and Berthoz, 1979) are much more influential under compliant or moving support surface conditions.

Efficacy of support surface and visual stabilization. Stabilizing the rotational positions of the ankle joints during AP sway eliminated not only the automatic component of EMG adjustment but also the resistance provided by the inherent stiffness of the lower leg musculature. Based upon the $\pm 5 \%$ error estimates, the stabilization procedure should have eliminated at least $95 \%$ of the resistance due to inherent stiffness and reduced swayrelated rotational inputs at the ankle joints to less than $5 \%$ of normal. Based upon these error estimates and actual measurements of sway motion, we calculated the maximum support surface and visual stimulus rates which could have occurred during stabilized performance trials: rates of ankle rotation under stabilized ankle conditions were estimated at less than $0.4^{\circ} / \mathrm{sec}$ during performance trials and $1.0^{\circ} / \mathrm{sec}$ during transient support surface perturbations. Both of these stimulus rate values are below the $2.5^{\circ} / \mathrm{sec}$ ankle rotation rate found to be the minimum necessary for rapid muscle activation during stance (Nashner and Cordo, 1981). Maximum estimated rates of visual inputs during stabilization procedures were less than $0.5 \mathrm{~cm} / \mathrm{sec}$ during performance trials and $1.5 \mathrm{~cm} / \mathrm{sec}$ during the most rapid AP sway perturbations. While minimum rates for visually induced postural activity have not been reported, linear vection was produced at rates of visual motion as low as $3 \mathrm{~cm} / \mathrm{sec}$ and subjects could detect linear motion of the visual surround subjectively at rates as low as $1 \mathrm{~cm} / \mathrm{sec}$ (Berthoz et al., 1975). Assuming that the thresholds for visual input to equilibrium control are similar to the above values, the stabilization procedure reduced visual inputs to below threshold levels in all instances with the possible exception of brief intervals during the most rapid of sway perturbations.

The above threshold calculations also may explain why the more impaired patients tended to lose balance abruptly under conflict conditions when stabilizing gains were increased beyond 0.7 to 0.8 . At these levels of 
stabilization, subjects received approximately 20 to $30 \%$ of the normal input motion from support and visual surfaces. This level of stimulation would have produced maximum rotation rates about the ankles of 3 to $6^{\circ} / \mathrm{sec}$ and maximum linear movement rates of 2 to $4 \mathrm{~cm} / \mathrm{sec}$ in the visual field. Both of these values are slightly above documented threshold levels.

Fixed hierarchical organization of sensory inputs. We propose that the rapid reorganization of sensory inputs to posture is not adaptive in the true sense of the term but is rather a fixed hierarchical process in which the context-dependent weighting of sensory inputs acting at a lower level is established by a fixed higher level process. Experimental findings indicate that the major criterion for the short term weighting of support surface and visual inputs during stance is the congruence of each of these senses with the inertial-gravitational reference provided by the vestibular system; conflicting orientation inputs from these two senses are suppressed quickly in favor of those congruent with the internal reference. Our approach to substantiating this hypothesis has been to demonstrate experimentally the inherent limitations of this reorganizational strategy. Specifically, there is no internal mechanism for distinguishing between the discongruence caused by external disturbances and that arising from pathological changes in the vestibular reference itself.

Two qualifications to the above hypothesis are, however, essential. First, it was based upon tests of vestibular patients who were not experiencing vertigo or other clinical signs suggesting hyperactive (rather than hypoactive) inputs or components of vestibular activity unrelated to head motion. While "erroneous" inputs as well as the lack of vestibular inputs might disrupt the sensory organizational strategy, it is also possible that there are fundamental differences among these latter categories of patients. Second, the abnormalities of the vestibular patients that we tested were different from those reported earlier for a group of cerebellar deficit patients (Nashner, 1976; Nashner and Grimm, 1977). While the amplitude changes of automatic postural adjustments of vestibular patients were large but not systematically related to context, patients with cerebellar deficits assumed a relatively fixed weighting of inputs under all conditions.

What may be considered adaptive changes in strategy do, no doubt, occur but probably over a much longer time interval. The herein described organizational changes in support surface and visual inputs were significantly more rapid than several previously described adaptive processes. For example, subjects wore reversing prisms a weck or more before significant VOR gain adaptation was noted (Gonshor and Melvill Jones, 1976). Gain of a reflex presumed to be otolith-spinal in origin changed only after subjects moved actively for periods of $8 \mathrm{hr}$ within an altered gravitational environment (Watt and Zucker, 1980). These much slower adaptive changes in the VOR and otolith-spinal reflexes, however, probably involved changes in the vestibular reference itself. Subjects were forced to accommodate the VOR to an optically reversed visual environment by progressively attenuating and, in some instances, actually reversing the direction of reflex eye movements in response to head rotation.

Several studies of perceptual adaptation to altered environments also included fixed hierarchical as well as truly adaptive processes. The use of $a$ priori knowledge and "efference copy" to anticipate the outcome of intentional actions and then to compare anticipated and actual responses were fundamental concepts in several of these studies (e.g., von Holst and Mittelstaedt, 1950; Held, 1961; Young, 1970). Based upon these constructs, Oman (1980) termed "nonadaptive" those processes which continuously reweighted inputs utilizing a fixed "internal model" of the sensory context. He termed "adaptive" the much more complex processes which modified the internal model following its failure within a new sensory context to distinguish adequately among self and external object motions. Thus, according to this definition, rapid reorganization of sensory inputs to posture would be a fixed "nonadaptive" process, while prism-induced changes in the VOR gain is an example of an "adaptive" process.

\section{References}

Begbie, G. H. (1967) Some problems of postural sway. In Myotatic, Kinesthetic, and Vestibular Mechanism, A. V. S. de Reuck and J. Knight, eds., pp. 80-92, Churchill Ltd., London.

Berthoz, A., B. Pavard, and L. R. Young (1957) Perception of linear horizontal selfmotion induced by peripheral vision (linear vection). Basic characteristics and visual-vestibular interactions. Exp. Brain Res. 23: 471-498.

Black, F. O., C. Wall, III, and D. O'Leary (1978) Computerized screening of the human vestibulospinal system. Ann. Otol. Rhinol. Laryngol. 87: 853-864.

Dichgans, J., K. H. Mauritz, J. H. J. Allum, and T. Brandt (1975) Postural sway in normal and ataxic patients: Analysis of the stabilizing and destabilizing effects of vision. Agressologie 17: 15-24.

Gonshor, A., and G. Melvill Jones (1976) Extreme vestibuloocular adaptation induced by prolonged optical reversal of vision. J. Physiol. (Lond.) 256: 381-414.

Gurfinkel, V. S., Ya. M. Kots, Y. I. Pal'tseu, and A. G. Feldman (1971) The compensation of respiratory disturbances of the erect posture of man as an example of the organization of interarticular interaction. In Models of the Structural-Functional Organization of Certain Biological Systems, V. S. Gurfinkel, S. V. Fomin, and M. L. Tsetlin, eds., pp. 382-395, MIT Press, Cambridge, MA.

Gurfinkel, V. S., M. I. Lipshits, and K. Ye. Popov (1974) Is the stretch reflex the main mechanism in the system of regulation of the vertical posture of man? Biophysics (Engl. Transl. Biofizika) 19: 744-748.

Held, R. (1961) Exposure history as a factor in maintaining stability of perception and coordination. J. Nerv. Ment. Dis. 132: 26-32.

Lee, D. N., and J. R. Lishman (1975) Visual proprioceptive control of stance. J. Hum. Move. Stud. 1: 87-95.

Lestienne, F., J. F. Soechting, and A. Berthoz (1977) Postural readjustments induced by linear motion of visual scenes. Exp. Brain Res. 28: 363-384.

Martin, J. P. (1965) Tilting reactions and disorders of the basal ganglia. Brain 88: 855-874.

Meiry, J. L. (1966) The Vestibular System and Human Dynamic Space Orientation, NASA-CR-628, NASA Scientific and Technical Information Facility, Baltimore/Washington International Airport, MD. 
Nashner, L. M. (1971) A model describing the vestibular detection of body sway motion. Acta Otolaryngol. (Stockh.) 72: $429-436$.

Nashner, L. M. (1972) Vestibular posture control model. Kybernetik 10: 106-110.

Nashner, L. M. (1976) Adopting reflexes controlling the human posture. Exp. Brain Res. 26: 59-72.

Nashner, L. M. (1977) Fixed patterns of rapid postural responses among leg muscles during stance. Exp. Brain Res. 30: 13-24.

Nashner, L. M., and A. Berthoz (1978) Visual contribution to rapid motor responses during posture control. Brain Res. 150: 403-407.

Nashner, L. M., and P. J. Cordo (1981) Relation of postural responses and reaction-time voluntary movements in human leg muscles. Exp. Brain Res. 43: 395-405.

Nashner, L. M., and R. J. Grimm (1977) Analysis of multiloop dyscontrols in standing cerebellar patients. Prog. Clin. Neurophysiol. 4: 300-319.

Nashner, L. M., M. Woollacott, and G. Tuma (1979) Organization of rapid response to postural and locomotor-like perturbations of standing man. Exp. Brain Res. 36: 463-476.

Oman, C. M. (1980) A Heuristic Mathematical Model for the
Dynamics of Sensury Conflict and Motion Sickness, MVT. 80-1, MIT Press, Cambridge, MA.

Soechting, J. F., and A. Berthoz (1979) Dynamic role of vision in the control of posture in man. Exp. Brain Res. 36: 551-561.

Talbott, R. E., and J. M. Brookhart (1980) A predictive model study of the visual contribution to canine posture control. Am. J. Physiol. 239: (Regulatory Integrative Comp. Physiol. 8) R80-R92.

von Holst, E., and H. Mittelstaedt (1950) Das Reafferenzprinzip (Wechselwirkungen zwischen Zentralnervensystem und Peripherie. Naturwissenschaften 37: 464-476.

Wall, C., III, F. O. Black, and D. P. O'Leary (1978) Clinical use of pseudorandom binary sequence white noise in assessment of the human vestibulo-ocular system. Ann. Otol. Rhinol. Laryngol. 87: 845-852.

Watt, D. G. D., and H. A. Zucker (1980) Adaptation of an otolith-spinal reflex during prolonged exposure to altered gravity. Soc. Neurosci. Abstr. 6: 558 .

Young, L. R. (1970) On visual vestibular interaction. In Proceedings of the Fifth Symposium on the Role of the Vestibular Organs in Space Exploration, NASA SP-314, pp. 205-210, NASA Scientific and Technical Information Facility, Baltimore/Washington International Airport, MD. 